\title{
Feasibility and diagnostic reliability of quantitative flow ratio in the assessment of non-culprit lesions in acute coronary syndrome
}

\author{
Aslihan Erbay ${ }^{1,2} \cdot$ Lisa Penzel $^{1,2} \cdot$ Youssef S. Abdelwahed ${ }^{1,2}$. Jens Klotsche ${ }^{3,4} \cdot$ Anne-Sophie Schatz ${ }^{1,2}$. \\ Julia Steiner $^{1,2} \cdot$ Arash Haghikia $^{1,2} \cdot$ Ulf Landmesser ${ }^{1,2,5} \cdot$ Barbara E. Stähli $^{1,2,6}$. David M. Leistner ${ }^{1,2,5}$
}

Received: 13 January 2021 / Accepted: 15 February 2021 / Published online: 2 March 2021

(c) The Author(s) 2021

\begin{abstract}
Several studies have demonstrated the feasibility and safety of hemodynamic assessment of non-culprit coronary arteries in setting of acute coronary syndromes (ACS) using fractional flow reserve (FFR) measurements. Quantitative flow ratio (QFR), recently introduced as angiography-based fast FFR computation, has been validated with good agreement and diagnostic performance with FFR in chronic coronary syndromes. The aim of this study was to assess the feasibility and diagnostic reliability of QFR assessment during primary PCI. A total of 321 patients with ACS and multivessel disease, who underwent primary PCI and were planned for staged PCI of at least one non-culprit lesion were enrolled in the analysis. Within this patient cohort, serial post-hoc QFR analyses of 513 non-culprit vessels were performed. The median time interval between primary and staged PCI was 49 [42-58] days. QFR in non-culprit coronary arteries did not change between acute and staged measurements $(0.86$ vs $0.87, \mathrm{p}=0.114)$, with strong correlation $(\mathrm{r}=0.94, \mathrm{p} \leq 0.001)$ and good agreement (mean difference $-0.008,95 \%$ CI $-0.013-0.003$ ) between measurements. Importantly, QFR as assessed at index procedure had sensitivity of $95.02 \%$, specificity of $93.59 \%$ and diagnostic accuracy of $94.15 \%$ in prediction of QFR $\leq 0.80$ at the time of staged PCI. The present study for the first time confirmed the feasibility and diagnostic accuracy of non-culprit coronary artery QFR during index procedure for ACS. These results support QFR as valuable tool in patients with ACS to detect further hemodynamic relevant lesions with excellent diagnostic performance and therefore to guide further revascularisation therapy.
\end{abstract}

Keywords Acute coronary syndrome $\cdot$ Fractional flow reserve $\cdot$ Quantitative flow ratio $\cdot$ Percutaneous coronary intervention

Abbreviations

3D-QCA Three-dimensional quantitative coronary angiography

ACS Acute coronary syndrome

David M. Leistner

david-manuel.leistner@charite.de

1 Department of Cardiology, Charité - University Medicine Berlin, Campus Benjamin Franklin, Hindenburgdamm 30, 12203 Berlin, Germany

2 DZHK (German Centre for Cardiovascular Research), Partner Site Berlin, Berlin, Germany

3 German Rheumatism Research Centre Berlin, Berlin, Germany

4 Institute for Epidemiology and Health Care Economics, Charité - University Medicine Berlin, Berlin, Germany

5 Berlin Institute of Health (BIH), Berlin, Germany

6 Department of Cardiology, University Heart Centre, University Hospital Zurich, Zurich, Switzerland
CABG Coronary artery bypass grafting

CCS Chronic coronary syndrome

FFR Fractional flow reserve

iFR Instantaneous wave-free ratio

LVEF Left ventricular ejection fraction

NSTE-ACS Non-ST segment elevation acute coronary syndrome

PCI Percutaneous coronary intervention

QFR Quantitative flow ratio

STE-ACS ST segment elevation acute coronary syndrome

\section{Introduction}

Multivessel coronary artery disease is encountered in about half of patients with acute coronary syndromes (ACS) [1-3] and is associated with an increased risk for adverse events [2-4]. Benefits of complete over culprit vessel only 
revascularization have been demonstrated in several studies $[5,6]$. Invasive pressure-derived fractional flow reserve (FFR) has been established as gold standard for functional lesion assessment in chronic coronary syndromes (CCS) [7-9] and proves supportive results for non-culprit lesion interrogation in ACS patients [10,11]. Resting indices such as instantaneous wave-free ratio (iFR) have also shown reasonable correlations with FFR-assessment and advantages in clinical outcome [12-14]. In patients with ACS, there is some concern that microvascular dysfunction in a highly prothrombotic and inflammatory setting could prevent reliable functional assessment of non-culprit coronary lesions [15]. However, several studies have proven the feasibility and safety of FFR measurements for non-culprit coronary arteries during ACS considering follow-up measurements as a reference $[14,16,17]$. Similarly, serial measurements of the index of microcirculatory resistance (IMR) demonstrated no significant difference between immediate and follow-up assessment [17].

Angiography-derived quantitative flow ratio (QFR) was introduced as fast FFR computation without the need for pressure wire advancement or the hyperemia induction. Large prospective trials have validated and the feasibility and diagnostic performance of QFR in comparison to FFR and resting indices [18-21]. However, data on the validity of QFR in setting of ACS are scarce.

Therefore, the aim of this study was to assess the feasibility and diagnostic reliability of QFR in non-culprit vessels of ACS patients.

\section{Methods}

\section{Study population}

A total of 1,436 patients from the Charité Cath registry, who underwent PCI for ACS between February 2014 and March 2017 at the Department of Cardiology, Charité - University Medicine Berlin, Germany, were screened for inclusion in the study. The final analysis included a total of 321 patients with planned staged PCI within six months of at least one non-culprit lesion based on visual lesion estimation of $>70 \%$ diameter stenosis on coronary angiogram at time of index ACS event (Fig. 1).

Exclusion criteria comprised ACS complicated by cardiogenic shock or resuscitation, Type 2 myocardial infarction, prior coronary artery bypass grafting (CABG), indication for $\mathrm{CABG}$, atrial fibrillation, bifurcation lesions with medina classification 1-1-1, ostial lesions and angiographic characteristics precluding high-quality QFR analysis such as suboptimal angiographic image quality, lack of two projections at least $25^{\circ}$ apart, suboptimal contrast filling, vessel overlap, or vessel foreshortening. Further, non-culprit arteries with

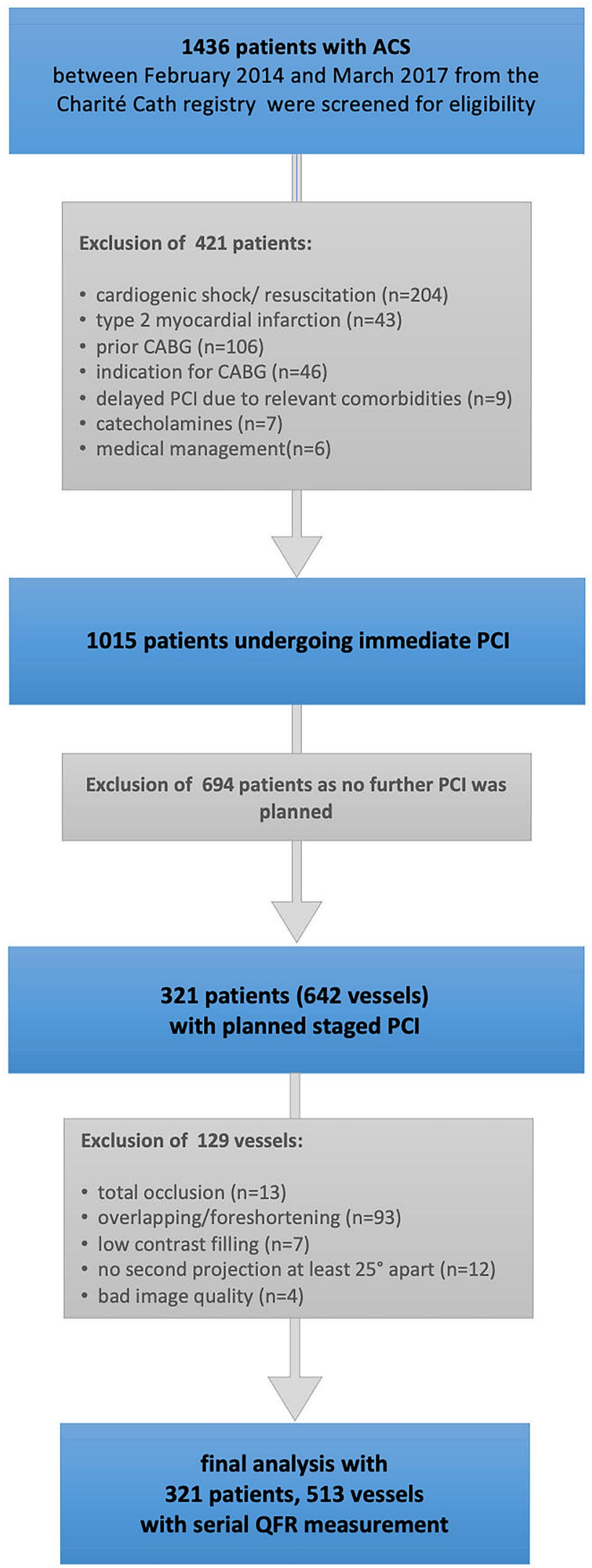

Fig. 1 Study flow chart 
chronic total occlusions or those undergoing immediate PCI during the index ACS procedure were excluded (Fig. 1). The registry comprised baseline characteristics, laboratory data, procedural data for the index ACS event as well as the staged procedure. All patients received evidence-based medical management and were treated with PCI according to current guidelines for myocardial revascularization and ACS [22-24].

The study was performed in accordance with the principles of the Declaration of Helsinki and local law and regulations. Ethical approval of the institutional review board was obtained.

\section{Quantitative flow ratio (QFR) analysis}

Functional assessment of non-culprit coronary arteries was analysed by two certified investigators performing post-hoc three-dimensional quantitative coronary angiography (3DQCA) and QFR analyses at the institution's imaging core laboratory. As previously described [18, 19, 25], two angiographic projections after administration of nitroglycerine at least $25^{\circ}$ apart with less vessel overlap and good contrast filling in the end-diastolic frames were chosen for high quality QFR analyses. After optimization of automatically detected vessel contours, the $3 \mathrm{D}$ vessel reconstruction was performed. In a final step, frame counting with a record of at least 12.5 frames/second allowed the calculation of contrastflow vessel QFR (Fig. 2). The QFR investigators did not perform QFR of index and staged angiogram subsequently and were blinded to other QFR results.

\section{Statistical analysis}

As descriptive measures, categorical variables were presented as numbers and percentages.

All continuous variables were tested for normality of distribution by the Shapiro-Wilks test and presented as mean \pm standard deviation (SD) or median and interquartile range (IQR) as appropriate. Baseline characteristics were analysed at the patient level $(n=321)$, lesion characteristics and functional indices at the vessel level $(n=513)$, respectively. Acute and staged measurements of QFR and anatomic indices were compared by the Wilcoxon signed-rank test. The Spearman's rank correlation coefficient specified
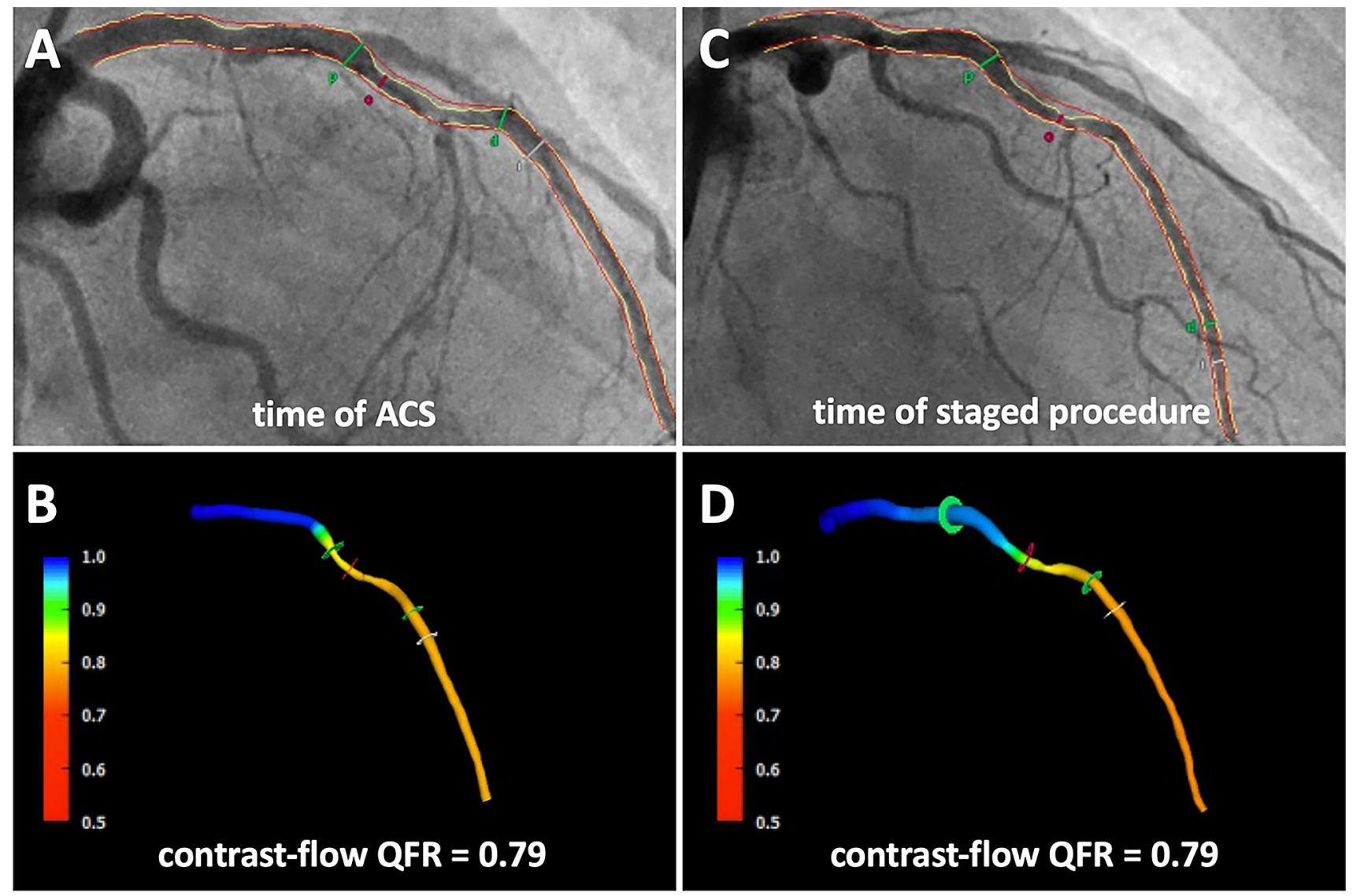

Fig. 2 Representative case with coronary angiogram and QFR measurement of a non-culprit lesion in the medial left anterior descending coronary artery (LAD) at the time of index ACS event $(\mathbf{a}, \mathbf{b})$ and staged procedure $(\mathbf{c}, \mathbf{d})$ 
the correlation between QFR at time of ACS index event and staged procedure. The agreement between serial QFR measurements was determined by Bland-Altman analysis. Sensitivity, specificity, positive predictive value (PPV), negative predictive value (NPV), positive likelihood ratio (+LR), negative likelihood ratio (- LR), and diagnostic accuracy for predicting a hemodynamically significant coronary lesion as defined by a QFR $\leq 0.80$ at the time of staged procedure were assessed. The cut-off values of 0.80 for QFR $[18,19],>50 \%$ for diameter stenosis $[18,25]$, and $\geq 58 \%$ for area stenosis [26] were based on prior studies. A two-sided p-value of $<0.05$ was considered statistically significant. All analyses were performed using IBM-SPSS version 26 (IBM Corp., Chicago, IL, USA).

\section{Results}

\section{Baseline characteristics}

Baseline patient and lesion characteristics are presented in Table 1. Median age was 66 [58-76] years, $27.1 \%$ were women. A total of $162(50.5 \%)$ and $159(49.5 \%)$ patients presented with ST segment elevation ACS (STE-ACS) and non-ST segment elevation ACS (NSTE-ACS), respectively. Within the study cohort, cardiovascular risk factors were

Table 1 Baseline patient characteristics

\begin{tabular}{ll}
\hline At the patient level $(\mathrm{n}=321)$ & \\
\hline Type of ACS & $162(50.5)$ \\
STE-ACS & $159(49.5)$ \\
NSTE-ACS & $66[58-76]$ \\
Age (years) & $234(72.9)$ \\
Male gender & \\
Medical history & $67(20.9)$ \\
Diabetes mellitus & $304(94.7)$ \\
Hypertension & $173(53.9)$ \\
Dyslipidemia & $42(13.1)$ \\
Prior PCI & $31(9.7)$ \\
Prior MI & $158(49.2)$ \\
Extent of CAD two-vessel-disease & $163(50.8)$ \\
Three-vessel-disease & $804[328.50-1845.50]$ \\
Maximum CK level (IU/litre) & $53[45-60]$ \\
LVEF (\%) &
\end{tabular}

Values are given as median and interquartile range or counts and percentages

ACS acute coronary syndrome, STE-ACS ST segment elevated acute coronary syndrome, NSTE-ACS non-ST segment elevated acute coronary syndrome, $P C I$ percutaneous coronary intervention, $M I$ myocardial infarction, $C A D$ coronary artery disease, $C K$ creatine kinase, $L V E F$ left ventricular ejection fraction frequently present such as hypertension in $94.7 \%$ or diabetes in $23 \%$ of patients. The median time interval between index and staged coronary angiography was 49 [42-58] days. Out of the analysed non-culprit vessels, 165 (32.2\%) were left anterior descending arteries (LAD), 216 (42.1\%) left circumflex arteries (LCX) or dominant obtuse marginal branches $(\mathrm{OM})$, and $132(25.7 \%)$ right coronary arteries (RCA).

\section{Functional assessment of non-culprit vessels}

In 521 coronary arteries, serial 3D-QCA and QFR analyses were performed. Minimum lumen diameter of the analysed non-culprit vessels was $1.4[1.0-1.8] \mathrm{mm}$ at baseline and $1.3[1.0-1.8] \mathrm{mm}$ at follow-up, while the diameter stenosis was $46.6[36.2-57.3] \%$ and 45.3 [35.2-56.1]\%, respectively. Hemodynamic significance defined as QFR $\leq 0.80$ was observed in $211(41.1 \%)$ non-culprit vessels at time of ACS and in 201 (39.2\%) vessels at staged procedure.

\section{Feasibility and diagnostic reliability of QFR in ACS}

Contrast-flow vessel QFR in non-culprit coronary arteries was comparable between acute and staged measurements $(0.86$ [0.74-0.97] vs. 0.87 [0.75-0.97], $\mathrm{p}=0.11)$ (Table 2). Strong correlation $(\mathrm{r}=0.94$ (95\% CI 0.93-0.95), $\mathrm{p} \leq 0.001$ ) and good agreement (mean difference -0.008 , 95\% CI -0.013-0.003) between serial QFR measurements were observed (Fig. 3). Importantly, QFR as assessed at index procedure had high sensitivity $(95.0 \%)$, specificity (93.6\%), PPV (90.5\%), NPV (96.7\%), and diagnostic accuracy $(94.2 \%)$ in predicting QFR of $\leq 0.80$ at time of staged procedure (Table 3 ). Corresponding values for anatomic indices are given in Tables 2, 3.

Serial QFR measurements revealed 26 non-culprit lesions (5.1\%) whose QFR result at time of ACS were different at staged procedure. Out of these 26 non-culprit lesions, 18 lesions with hemodynamic relevance at time of ACS had no longer functional significance at staged procedure (QFR 0.76 [0.71-0.78] at baseline vs. QFR 0.85 [0.82-0.88] at follow-up, $\mathrm{p}<0.001)$. Otherwise, QFR revealed hemodynamic relevant stenoses at staged procedure in 8 cases which were not considered significant at time of ACS procedure (QFR 0.84 [0.83-0.87] at baseline vs. QFR 0.78 [0.76-0.80] at follow-up, $\mathrm{p}<0.05)$.

\section{Discussion}

The present study investigated for the first time the feasibility and diagnostic reliability of angiography-derived functional assessment of non-culprit vessels in ACS by post-hoc serial QFR measurements in a reasonable study 
Fig. 3 Correlation and agreement between serial QFR assessment and anatomic indices at baseline and staged procedure. a Correlation and Bland Altman plot between QFR at baseline and staged procedures. b Correlation and Bland Altman plot between diameter stenosis at baseline and staged procedures. c Correlation and Bland Altman plot between area stenosis at baseline and staged procedures
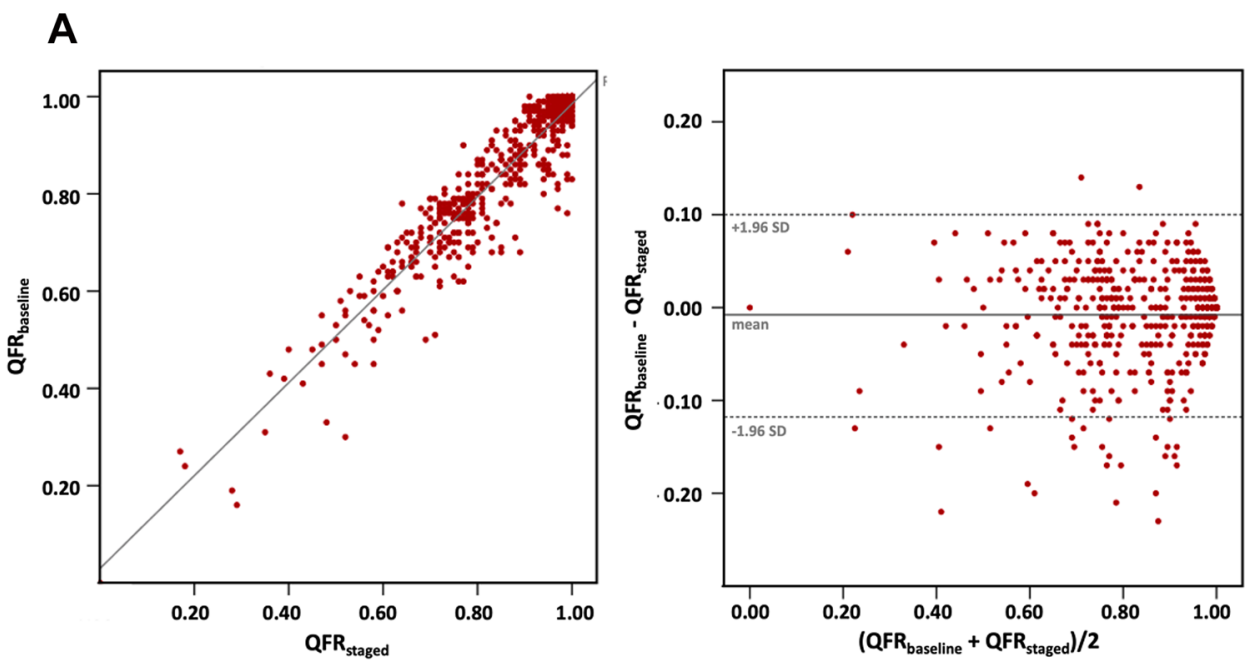

B
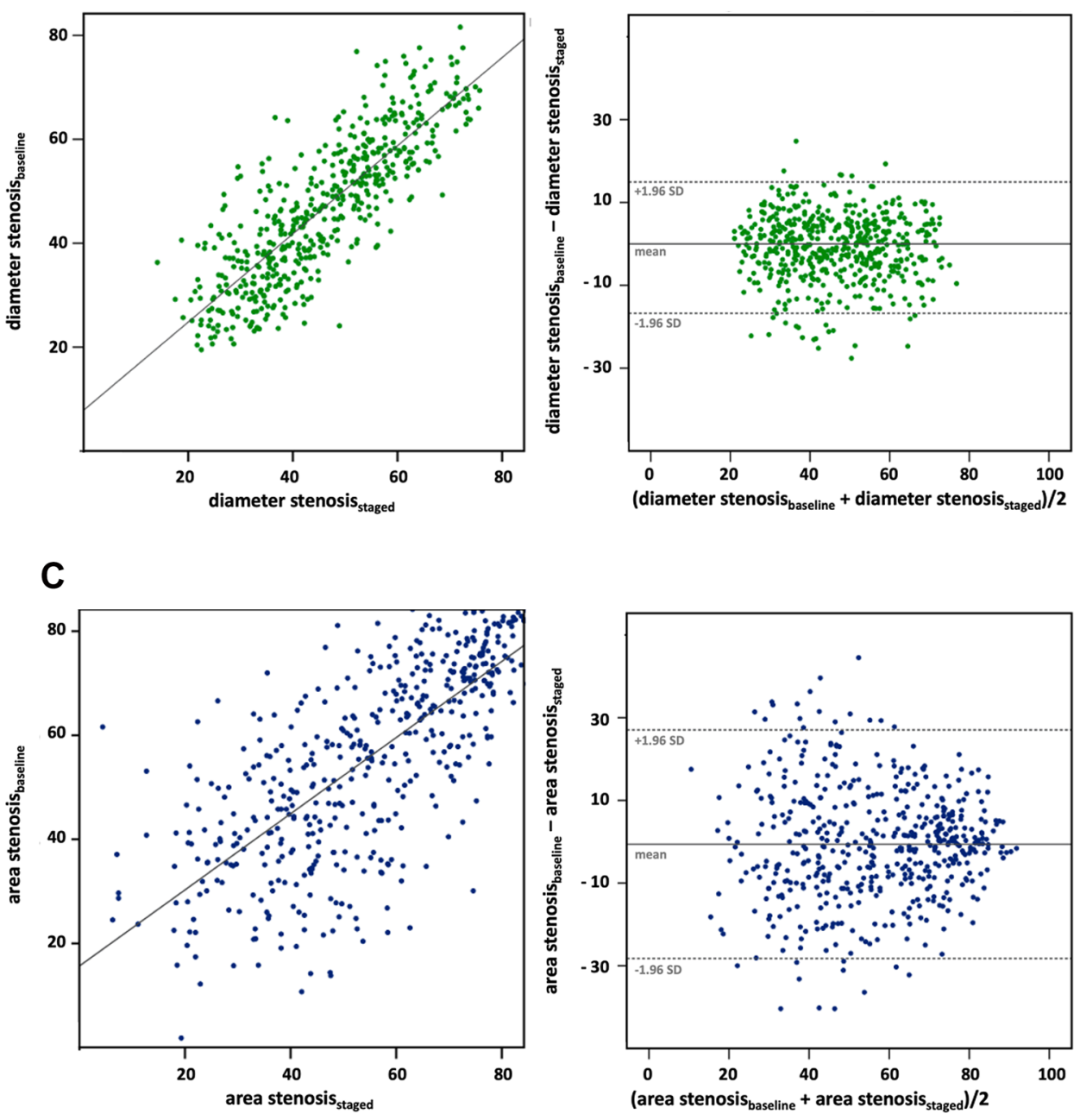
Table 2 Vessel characteristics at baseline and follow-up

\begin{tabular}{|c|c|c|c|}
\hline \multicolumn{4}{|l|}{ At the vessel level $(n=513)$} \\
\hline $\begin{array}{l}\text { Localization } \\
\text { LAD }\end{array}$ & & & $165(32.2)$ \\
\hline LCX/OM/IM & & & $216(42.1)$ \\
\hline \multirow[t]{2}{*}{ RCA } & & & $132(25.7)$ \\
\hline & Baseline & Follow-Up & p-value \\
\hline Fixed-flow vessel QFR & $0.86[0.74-0.97]$ & $0.87[0.75-0.97]$ & 0.309 \\
\hline Contrast-flow vessel QFR & $0.86[0.74-0.97]$ & $0.88[0.75-0.97]$ & 0.114 \\
\hline Lesion length (mm) & $17.50[10.80-26.55]$ & $16.80[10.05-26.70]$ & 0.487 \\
\hline Reference diameter (mm) & $2.70[2.30-3.00]$ & $2.60[2.20-3.00]$ & 0.008 \\
\hline Diameter stenosis (\%) & $46.60[36.20-57.25]$ & $45.30[35.20-56.05]$ & 0.098 \\
\hline Area stenosis $(\%)$ & $58.20[41.30-72.55]$ & $57.40[41.15-72.95]$ & 0.266 \\
\hline Minimum lumen diameter (mm) & $1.40[1.00-1.80]$ & $1.30[1.00-1.80]$ & 0.330 \\
\hline Plaque volume $\left(\mathrm{mm}^{3}\right)$ & $29.20[14.20-56.45]$ & $24.20[11.35-54.65]$ & 0.140 \\
\hline
\end{tabular}

Values are given as median and interquartile range or counts and percentages

$L A D$ left anterior descending coronary artery, $L C X$ left circumflex coronary artery, $O M$ obtuse marginal branch, $I M$ intermediate coronary artery, $R C A$ right coronary artery, $Q F R$ quantitative flow ratio

Table 3 Diagnostic performance of contrast-flow vessel QFR, diameter stenosis and area stenosis with staged indices as reference

\begin{tabular}{llll}
\hline $\mathrm{n}=513$ vessels & QFR $\leq 0.80$ & Diameter stenosis $\geq 50 \%$ & Area stenosis $\geq 58 \%$ \\
\hline Sensitivity & 95.02 & 85.99 & 84.25 \\
& $(91.04-97.59)$ & $(80.50-90.41)$ & $(79.18-88.50)$ \\
Specificity & 93.59 & 86.27 & 81.08 \\
& $(90.27-96.04)$ & $(81.90-89.93)$ & $(75.77-85.66)$ \\
Accuracy & 94.15 & 86.16 & 82.65 \\
& $(91.76-96.02)$ & $(82.87-89.03)$ & $(79.09-85.83)$ \\
Positive predictive value & 90.52 & 80.91 & 81.37 \\
& $(86.19-93.59)$ & $(76.09-84.95)$ & $(77.14-84.96)$ \\
Negative predictive value & 96.69 & 90.10 & 84.00 \\
Positive likelihood ratio & $(94.10-98.16)$ & $(86.62-92.75)$ & $(79.70-87.53)$ \\
& 14.82 & 6.27 & 4.45 \\
Negative likelihood ratio & $(9.69-22.68)$ & $(4.71-8.34)$ & $(3.44-5.76)$ \\
& 0.05 & 0.16 & 0.19 \\
Mean difference \pm SD & $(0.03-0.10)$ & $(0.12-0.23)$ & $(0.15-0.26)$ \\
\hline
\end{tabular}

population of ACS patients. Our findings demonstrate that hemodynamic assessment by QFR in the acute phase of ACS represents a robust diagnostic tool for non-culprit lesion assessment. In only $5.1 \%$ of patients, discordance in QFR values between the acute phase and the staged procedure were observed. Importantly, angiography-based QFR outperformed anatomic indices as assessed by 3D-QCA.

\section{Hemodynamic assessment of non-culprit lesions in ACS}

There is no doubt for primary PCI as the first-line therapy in patients with ACS [22-24]. Given that multivessel disease is present in about a half of ACS patients [1-3], the optimal treatment of non-culprit lesions is of substantial interest. The superiority of complete coronary revascularization over culprit-only PCI was proven in several studies $[5,6,10,11]$. An FFR-guided revascularization strategy further bears the advantage of achieving improved outcomes with a lower number of subsequent revascularizations and consecutivelylower health care costs [27].

\section{QFR as an alternative modality to invasive physiological assessment}

Quantitative flow ratio represents an angiography-based functional tool for the identification of ischemia-causing lesions by fast FFR computation. Limiting aspects 
of invasive FFR measurement such as additional instruments, prolongation of procedural duration, and an increased procedural risk by FFR-wire advancement and induction of hyperemia, along with increased procedural costs, can be completely avoided. Recently, it was demonstrated that the expenditure of time for QFR assessment was significantly less than the time to complete FFR measurement [19]. Thereby, QFR poses an attractive and well-suited tool for fast functional lesion assessment in the setting of ACS.

The present study now extends the findings regarding feasible and reliable functional lesion assessment in ACS from wire- and adenosine-based measurements to angiography-based functional lesion interrogation by demonstrating the high reproducibility and excellent diagnostic accuracy of QFR in a large cohort of patients with ACS and serial QFR measurements. Importantly, QFR outperformed anatomic indices such as diameter stenosis and bears the potential of a more accurate assessment of lesion severity. Our findings are in line with previous studies including patients with ACS and undergoing staged FFR evaluation [28-31]. The present results for serial QFR assessment underline the reliable performance of QFR in setting of ACS and provides a good basis for following outcome studies.

\section{Limitations}

A few limitations need to be considered. The present study was a retrospective and not previously specified analysis. As a result, 3D-QCA and QFR analyses were performed from available coronary angiographies which were not optimally obtained according to QFR acquisition guide and led to an exclusion of 129 (20.1\%) vessels due to suboptimal angiography or vessel overlap at acute or staged procedures. Nevertheless, the study represents a realistic impression of every-day clinical routine and a high-quality QFR analysis could be performed in 321 patients with 513 non-culprit vessels, corresponding to $79.9 \%$ of all eligible vessels. In addition, the reference was determined as QFR results from staged angiogram and no wire-based assessment by FFR as the actual gold standard in functional assessment of coronary lesions. Since the good correlation and diagnostic performance compared to FFR has been shown many times [18-21], this study focused on serial QFR measurement. The strong correlations observed in this study further support the wide applicability and feasibility of QFR in everyday clinical practice.

\section{Conclusion}

The present study demonstrates the feasibility and high diagnostic reliability of QFR assessment in non-culprit coronary arteries during ACS. These results support QFR as valuable tool for the detection of hemodynamic relevant lesions in patients with ACS. The prognostic impact of QFR and its role for PCI guidance in ACS has to be evaluated in future prospective randomized clinical outcome trials.

Author contributions All authors have read and approved submission of the manuscript. The manuscript has not been published and is not being considered for publication elsewhere in whole or part in any language except as an abstract. All authors contributed significantly to this work. Full disclosure of any potential conflict of interest is provided. All authors agree to be accountable for all aspects of the work in ensuring that questions related to the accuracy or integrity of any part of the work are appropriately investigated and resolved. Submission of the manuscript has been approved by all the authors. AE: conception and design of the study; collection, analysis and interpretation of data; drafting of the manuscript; final approval of the manuscript submitted. LP: conception and design of the study; collection, analysis and interpretation of data; drafting of the manuscript; final approval of the manuscript submitted. YSA: interpretation of data; revising the manuscript critically for important intellectual content; final approval of the manuscript submitted. JK:analysis and interpretation of data; revising the manuscript critically for important intellectual content; final approval of the manuscript submitted. ASS: interpretation of data; revising the manuscript critically for important intellectual content; final approval of the manuscript submitted. JS: interpretation of data; revising the manuscript critically for important intellectual content; final approval of the manuscript submitted. $\mathrm{AH}$ : interpretation of data; revising the manuscript critically for important intellectual content; final approval of the manuscript submitted. UL: interpretation of data; revising the manuscript critically for important intellectual content; final approval of the manuscript submitted. BES: conception and design of the study; collection, analysis and interpretation of data; revising the manuscript critically for important intellectual content; final approval of the manuscript submitted. DML: conception and design of the study; collection, analysis and interpretation of data; revising the manuscript critically for important intellectual content; final approval of the manuscript submitted.

Funding Open Access funding enabled and organized by Projekt DEAL.

Availability of data and material Data and material are available on request.

\section{Compliance with ethical standards}

Conflict of interest There are no conflicts of interest to declare.

Open Access This article is licensed under a Creative Commons Attribution 4.0 International License, which permits use, sharing, adaptation, distribution and reproduction in any medium or format, as long as you give appropriate credit to the original author(s) and the source, 
provide a link to the Creative Commons licence, and indicate if changes were made. The images or other third party material in this article are included in the article's Creative Commons licence, unless indicated otherwise in a credit line to the material. If material is not included in the article's Creative Commons licence and your intended use is not permitted by statutory regulation or exceeds the permitted use, you will need to obtain permission directly from the copyright holder. To view a copy of this licence, visit http://creativecommons.org/licenses/by/4.0/.

\section{References}

1. Park DW, Clare RM, Schulte PJ, Pieper KS, Shaw LK, Califf RM et al (2014) Extent, location, and clinical significance of noninfarct-related coronary artery disease among patients with STelevation myocardial infarction. JAMA 312(19):2019-2027. https ://doi.org/10.1001/jama.2014.15095

2. Sorajja P, Gersh BJ, Cox DA, McLaughlin MG, Zimetbaum P, Costantini $C$ et al (2007) Impact of multivessel disease on reperfusion success and clinical outcomes in patients undergoing primary percutaneous coronary intervention for acute myocardial infarction. Eur Heart J 28(14):1709-1716. https://doi.org/10.1093/eurhe artj/ehm184

3. Jensen LO, Terkelsen CJ, Horvath-Puho E, Tilsted HH, Maeng M, Junker A et al (2015) Influence of multivessel disease with or without additional revascularization on mortality in patients with ST-segment elevation myocardial infarction. Am Heart J 170(1):70-78. https://doi.org/10.1016/j.ahj.2015.03.020

4. Stone GW, Maehara A, Lansky AJ, de Bruyne B, Cristea E, Mintz GS et al (2011) A prospective natural-history study of coronary atherosclerosis. N Engl J Med 364(3):226-235. https://doi. org/10.1056/NEJMoa1002358

5. Gershlick AH, Khan JN, Kelly DJ, Greenwood JP, Sasikaran T, Curzen N et al (2015) Randomized trial of complete versus lesiononly revascularization in patients undergoing primary percutaneous coronary intervention for STEMI and multivessel disease: the CvLPRIT trial. J Am Coll Cardiol 65(10):963-972. https://doi. org/10.1016/j.jacc.2014.12.038

6. Mehta SR, Wood DA, Storey RF, Mehran R, Bainey KR, Nguyen $\mathrm{H}$ et al (2019) Complete revascularization with multivessel PCI for myocardial infarction. N Engl J Med 381(15):1411-1421. https ://doi.org/10.1056/NEJMoa1907775

7. Knuuti J, Wijns W, Saraste A, Capodanno D, Barbato E, FunckBrentano C et al (2020) 2019 ESC Guidelines for the diagnosis and management of chronic coronary syndromes. Eur Heart $\mathbf{J}$ 41(3):407-477. https://doi.org/10.1093/eurheartj/ehz425

8. Zimmermann FM, Omerovic E, Fournier S, Kelbæk H, Johnson NP, Rothenbühler M et al (2019) Fractional flow reserve-guided percutaneous coronary intervention vs. medical therapy for patients with stable coronary lesions: meta-analysis of individual patient data. Eur Heart J. 40(2):180-6. https://doi.org/10.1093/ eurheartj/ehy 812

9. Völz S, Dworeck C, Redfors B, Pétursson P, Angerås O, Gan LM et al (2020) Survival of patients with angina pectoris undergoing percutaneous coronary intervention with intracoronary pressure wire guidance. J Am Coll Cardiol 75(22):2785-2799. https://doi. org/10.1016/j.jacc.2020.04.018

10. Engstrøm T, Kelbæk H, Helqvist S, Høfsten DE, Kløvgaard L, Holmvang L et al (2015) Complete revascularisation versus treatment of the culprit lesion only in patients with ST-segment elevation myocardial infarction and multivessel disease (DANAMI-3 - PRIMULTI): an open-label, randomised controlled trial. Lancet 386(9994):665-671. https://doi.org/10.1016/s0140 $-6736(15) 60648-1$
11. Smits PC, Abdel-Wahab M, Neumann FJ, Boxma-de Klerk BM, Lunde K, Schotborgh CE et al (2017) Fractional flow reserveguided multivessel angioplasty in myocardial infarction. N Engl J Med 376(13):1234-1244. https://doi.org/10.1056/NEJMoa1701 067

12. Davies JE, Sen S, Dehbi HM, Al-Lamee R, Petraco R, Nijjer SS et al (2017) Use of the instantaneous wave-free ratio or fractional flow reserve in PCI. N Engl J Med 376(19):1824-1834. https:// doi.org/10.1056/NEJMoa1700445

13. Götberg M, Christiansen EH, Gudmundsdottir IJ, Sandhall L, Danielewicz M, Jakobsen L et al (2017) Instantaneous wave-free ratio versus fractional flow reserve to guide PCI. N Engl J Med 376(19):1813-1823. https://doi.org/10.1056/NEJMoa1616540

14. Musto C, De Felice F, Rigattieri S, Chin D, Marra A, Nazzaro MS et al (2017) Instantaneous wave-free ratio and fractional flow reserve for the assessment of nonculprit lesions during the index procedure in patients with ST-segment elevation myocardial infarction: The WAVE study. Am Heart J 193:63-69. https://doi. org/10.1016/j.ahj.2017.07.017

15. Fearon WF, De Bruyne B, Pijls NHJ (2016) Fractional flow reserve in acute coronary syndromes. J Am Coll Cardiol 68(11):1192-1194. https://doi.org/10.1016/j.jacc.2016.07.713

16. Choi KH, Lee JM, Kim HK, Kim J, Park J, Hwang D et al (2018) Fractional flow reserve and instantaneous wave-free ratio for nonculprit stenosis in patients with acute myocardial infarction. JACC Cardiovasc Interv 11(18):1848-1858. https://doi.org/10.1016/j. jcin.2018.06.045

17. Ntalianis A, Sels JW, Davidavicius G, Tanaka N, Muller O, Trana $\mathrm{C}$ et al (2010) Fractional flow reserve for the assessment of nonculprit coronary artery stenoses in patients with acute myocardial infarction. JACC Cardiovasc Interv 3(12):1274-1281. https://doi. org/10.1016/j.jcin.2010.08.025

18. Tu S, Westra J, Yang J, von Birgelen C, Ferrara A, Pellicano M et al (2016) Diagnostic accuracy of fast computational approaches to derive fractional flow reserve from diagnostic coronary angiography: the International Multicenter FAVOR Pilot Study. JACC Cardiovasc Interv 9(19):2024-2035. https://doi.org/10.1016/j. jcin.2016.07.013

19. Westra J, Andersen BK, Campo G, Matsuo H, Koltowski L, Eftekhari A et al (2018) Diagnostic performance of in-procedure angiography-derived quantitative flow reserve compared to pressure-derived fractional flow reserve: the FAVOR II Europe-Japan Study. J Am Heart Assoc. https://doi.org/10.1161/ JAHA.118.009603

20. Stähli BE, Erbay A, Steiner J, Klotsche J, Mochmann HC, Skurk C et al (2019) Comparison of resting distal to aortic coronary pressure with angiography-based quantitative flow ratio. Int J Cardiol 279:12-17. https://doi.org/10.1016/j.ijcard.2018.11.093

21. Emori H, Kubo T, Kameyama T, Ino Y, Matsuo Y, Kitabata $\mathrm{H}$ et al (2018) Quantitative flow ratio and instantaneous wave-free ratio for the assessment of the functional severity of intermediate coronary artery stenosis. Coron Artery Dis. https://doi.org/10.1097/ MCA.0000000000000650

22. Neumann FJ, Sousa-Uva M, Ahlsson A, Alfonso F, Banning AP, Benedetto U et al (2019) 2018 ESC/EACTS Guidelines on myocardial revascularization. Eur Heart J 40(2):87-165. https://doi. org/10.1093/eurheartj/ehy394

23. Ibanez B, James S, Agewall S, Antunes MJ, Bucciarelli-Ducci C, Bueno $\mathrm{H}$ et al (2017) ESC Guidelines for the management of acute myocardial infarction in patients presenting with ST-segment elevation: The Task Force for the management of acute myocardial infarction in patients presenting with ST-segment elevation of the European Society of Cardiology (ESC). Eur Heart J. https://doi. org/10.1093/eurheartj/ehx393

24. Collet J-P, Thiele H, Barbato E, Barthélémy O, Bauersachs J, Bhatt DL et al (2020) ESC Guidelines for the management of 
acute coronary syndromes in patients presenting without persistent ST-segment elevation: The Task Force for the management of acute coronary syndromes in patients presenting without persistent ST-segment elevation of the European Society of Cardiology (ESC). Eur Heart J. https://doi.org/10.1093/eurheartj/ehaa575

25. Xu B, Tu S, Qiao S, Qu X, Chen Y, Yang J et al (2017) Diagnostic accuracy of angiography-based quantitative flow ratio measurements for online assessment of coronary stenosis. J Am Coll Cardiol 70(25):3077-3087. https://doi.org/10.1016/j. jacc.2017.10.035

26. Yazaki K, Otsuka M, Kataoka S, Kahata M, Kumagai A, Inoue $\mathrm{K}$ et al (2017) Applicability of 3-dimensional quantitative coronary angiography-derived computed fractional flow reserve for intermediate coronary stenosis. Circ J 81(7):988-992. https://doi. org/10.1253/circj.CJ-16-1261

27. Smits PC, Laforgia PL, Abdel-Wahab M, Neumann FJ, Richardt G, Boxma-de Klerk B et al (2020) Fractional flow reserveguided multivessel angioplasty in myocardial infarction: threeyear follow-up with cost benefit analysis of the Compare-Acute trial. EuroIntervention 16(3):225-232. https://doi.org/10.4244/ EIJ-D-20-00012

28. Sejr-Hansen M, Westra J, Thim T, Christiansen EH, Eftekhari A, Kristensen SD et al (2019) Quantitative flow ratio for immediate assessment of nonculprit lesions in patients with ST-segment elevation myocardial infarction-An iSTEMI substudy. Catheter Cardiovasc Interv. https://doi.org/10.1002/ccd.28208

29. Lauri FM, Macaya F, Mejía-Rentería H, Goto S, Yeoh J, Nakayama M et al (2020) Angiography-derived functional assessment of non-culprit coronary stenoses in primary percutaneous coronary intervention. EuroIntervention 15(18):e1594-e1601. https://doi. org/10.4244/EIJ-D-18-01165

30. Spitaleri G, Tebaldi M, Biscaglia S, Westra J, Brugaletta S, Erriquez A et al (2018) Quantitative flow ratio identifies nonculprit coronary lesions requiring revascularization in patients with STsegment-elevation myocardial infarction and multivessel disease. Circ Cardiovasc Interv 11(2):e006023. https://doi.org/10.1161/ CIRCINTERVENTIONS.117.006023

31. Tebaldi M, Biscaglia S, Erriquez A, Penzo C, Tumscitz C, Scoccia A et al (2020) Comparison of quantitative flow ratio, $\mathrm{Pd} / \mathrm{Pa}$ and diastolic hyperemia-free ratio versus fractional flow reserve in non-culprit lesion of patients with non ST-segment elevation myocardial infarction. Catheter Cardiovasc Interv. https://doi. org/10.1002/ccd.29380

Publisher's Note Springer Nature remains neutral with regard to jurisdictional claims in published maps and institutional affiliations. 